\title{
A polifonia nos gêneros acadêmicos e formulaicos: a construção de sentidos a partir da evocação da palavra alheia
}

\author{
Polyphony in academic and formulaic genres: \\ meaning production through introducing the other words
}

Erivaldo Pereira do Nascimento

Universidade Federal da Paraíba - João Pessoa - Paraíba - Brasil

$\diamond$

\begin{abstract}
Resumo: Este artigo objetiva analisar o fenômeno da polifonia enunciativa, principalmente da polifonia de locutores, e sua aplicação na descrição do funcionamento semântico-discursivo de diferentes gêneros dos universos empresarial/oficial e acadêmico. Especificamente, sistematizamos e refletimos sobre uma série de investigações ligadas ao projeto "Estudos Semântico-Argumentativos de Gêneros do Discurso: gêneros acadêmicos e formulaicos (ESAGD)", executado na Universidade Federal da Paraíba. Fundamentamo-nos teoricamente nos estudos sobre o fenômeno da polifonia a partir de Ducrot (1997, 1988), Anscombre (2005, 2010), Nascimento (2005) e Moyano (2007), entre outros. A partir dos dados levantados nos diferentes corpora descritos ou em descrição, conseguimos verificar que o locutor responsável pelo discurso como um todo, ao introduzir o discurso alheio em seu texto, produz diferentes efeitos de sentidos, entre os quais assimilação, distanciamento e avaliação. Esses efeitos de sentido, por sua vez, são indispensáveis para a própria manutenção do status quo das atividades humanas a que pertencem os gêneros investigados.
\end{abstract}

Palavras-chave: Polifonia de locutores; Efeitos de sentido; Gêneros acadêmicos e formulaicos.

\begin{abstract}
This paper aims to analyze the polyphony of enunciation phenomenon, mainly the polyphony of locutors, and its application to describe the semantic and discursive characteristic of different academic and business genres. Specifically we systematize and categorize some investigations correlated to the project called "Estudos Semântico-Argumentativos de Gêneros do Discurso: gêneros acadêmicos e formulaicos (ESAGD)", which is developed at Universidade Federal da Paraíba. The theoretical references used to the research are composed by the studies of polyphony by Ducrot $(1997,1988)$, Anscombre $(2005,2010)$, Nascimento (2005) and Moyano (2007), among others. From the collected data in different corpora it was possible to verify that the locutor responsible by the speech produces different meaning effects when introduces the others voices, such as assimilation, distance and evaluation. These meaning effects are necessary to maintain the status quo of the human activities that produce the described genres.
\end{abstract}

Keywords: Locutor Polyphony; Meaning effects; Academic and formulaic genres

No marco da Semântica Argumentativa, Oswald Ducrot $(1987$; 1988) propõe que a polifonia é constitutiva do sentido dos enunciados. Assim, descrever o sentido dos enunciados, e consequentemente do discurso, implica analisar os fenômenos polifônicos que os constituem. Dessa forma, o autor inaugura uma série de estudos sobre o fenômeno da polifonia, na língua e no discurso, que passou a ser denominada de Teoria Polifônica da Enunciação.

Considerando os pressupostos dessa teoria, propomos, neste trabalho, analisar o fenômeno da polifonia enunciativa, principalmente da polifonia de locutores, e sua aplicação na descrição do funcionamento semânticodiscursivo de diferentes gêneros discursivos dos universos empresarial/oficial e acadêmico. Em outras palavras, intencionamos refletir como os discursos relatados, uma das formas de polifonia enunciativa mostrada ou explícita, materializam-se em diferentes gêneros, imprimindo subjetividade e gerando diferentes efeitos de sentido.

De maneira específica, o presente trabalho sistematiza e reflete sobre uma série de investigações (algumas delas em curso) a respeito do fenômeno da polifonia em 
diferentes corpora, todas ligadas ao projeto "Estudos Semântico-Argumentativos de Gêneros do Discurso: gêneros acadêmicos e formulaicos (ESAGD)". O referido projeto está sendo executado em dois laboratórios da Universidade Federal da Paraíba (Laboratório de Estudos Linguísticos-LAEL e Laboratório SemânticoPragmático de Textos-LASPRAT) e visa descrever a estrutura semântico-argumentativa de diferentes gêneros discursivos, em especial dos gêneros acadêmicos e formulaicos (do universo empresarial e oficial).

Para o presente trabalho, fundamentamo-nos teoricamente nos estudos sobre o fenômeno da polifonia a partir de distintos autores, entre os quais Ducrot (1987, 1988), Anscombre (2005; 2010), Nascimento (2005) e Moyano (2007). Os dados levantados nos diferentes corpora - descritos ou em processo de descrição, através do projeto ESAGD - permitiram-nos uma reflexão mais profunda sobre o fenômeno da polifonia, de maneira especial sobre a polifonia de locutores. Particularmente, temos observado, nas análises dos diferentes corpora investigados, que o locutor que se apresenta como responsável pelo discurso como um todo, ao introduzir o discurso alheio em seu texto, produz diferentes efeitos de sentidos, entre os quais os efeitos de assimilação, distanciamento e avaliação, como veremos mais adiante.

Este trabalho está organizado em três seções. $\mathrm{Na}$ primeira trataremos, de maneira geral, dos princípios dos estudos da polifonia enunciativa, tal como proposto por Ducrot $(1987$; 1988). Na segunda, iremos nos deter, especificamente, à polifonia de locutores, apresentando uma proposta de reformulação à definição inicial de Ducrot para este tipo de polifonia e analisando esse fenômeno nos gêneros investigados pelo projeto ESAGD. Na terceira seção, trataremos do fenômeno da impessoalidade discursiva nos estudos polifônicos, com destaque para os estudos de Anscombre $(2005,2010)$, sobre a evocação do ON-locuteur (SE-locutor) no discurso, também aplicando aos gêneros descritos pelo referido projeto. Por fim, apresentaremos algumas considerações acerca da aplicação dos estudos da polifonia na descrição dos gêneros acadêmicos e formulaicos, ligados ao projeto ESAGD.

\section{Os estudos sobre a polifonia enunciativa}

O uso do termo polifonia, nos estudos da linguagem, foi introduzido por Bakhtin (2002a), em Problemas da Poética de Dostoiévski, quando o estudioso postulou a existência de dois tipos de literaturas: a dogmática, de tipo monológica, e a carnavalesca, popular ou polifônica. $\mathrm{Na}$ última ele incluiu a obra de Dostoiévski.

Bakhtin afirma que, na literatura polifônica, o personagem apresenta a si mesmo, é "o agente do discurso autêntico e não um objeto mudo do discurso do autor" (BAKHTIN, 2002a, p. 64). O autor, acrescenta Bakhtin, não fala do personagem, mas fala com ele, estabelecendo um diálogo constante na obra. Na literatura dogmática, por sua vez, a personagem é definida pelo autor, fechada e porta-voz de um ponto de vista do autor.

Ducrot $(1987 ; 1988)$ traz o termo polifonia para a Linguística, com o objetivo de questionar o princípio da unicidade do sujeito falante e, ao mesmo tempo, propor que o sentido dos enunciados é, por natureza, polifônico. Assim, pretende provar que um enunciado - "manifestação particular" ou "ocorrência hic et nunc de uma frase" (DUCROT, 1987, p. 164) - pode ser perpassado por mais de uma voz, ou seja, Ducrot pretende mostrar que o autor do enunciado não se expressa nunca diretamente, mas põe em cena, no mesmo enunciado, um certo número de personagens linguísticos.

Para Ducrot, a língua mesma dispõe de vários recursos linguísticos e fenômenos discursivos que permitem a construção de discursos polifônicos, entre os quais estão a pressuposição, a paráfrase e a negação.

A unicidade do sujeito é um postulado linguístico, segundo o qual em cada enunciado há somente uma pessoa que fala. De acordo com Ducrot (1987, p. 179), esse sujeito possuiria três propriedades: ser dotado de uma atividade psicofisiológica indispensável à produção do enunciado; ser o autor, responsável pelos atos ilocutórios (ordem, pergunta, asserção etc.) realizados na produção do discurso; ser designado em um enunciado pelas marcas de primeira pessoa (o eu que aparece no texto).

Segundo Ducrot (1987, p. 179), "considera-se como óbvio que este ser designado por eu é ao mesmo tempo o que produz o enunciado, e também aquele cujo enunciado expressa as promessas, asserções, etc.”. No entanto, no discurso direto é possível encontrar casos em que esse eu não se refere à pessoa que o pronuncia, mas a uma segunda pessoa, como no exemplo abaixo.

(1) Eu escutei quando Carlos falou: "eu estou muito cansado".

No exemplo (1), há duas marcas de $1^{\mathrm{a}}$ pessoa. A primeira se refere ao locutor responsável pelo enunciado como um todo e que o proferiu (doravante L1). O segundo $e u$, no entanto, não se refere a esse locutor, mas a um segundo locutor (L2 - Carlos), que é responsável pelo segmento "eu estou muito cansado". Entrou em cena, portanto, uma segunda pessoa do discurso (L2), a quem o segundo eu é atribuído.

Outro exemplo, citado por Ducrot (1987, p. 182), que coloca em questão as propriedades acima referidas, é o caso dos documentos escolares que os pais costumam assinar, autorizando seus filhos a realizarem determinada 
atividade. Esse tipo de correspondência possui, geralmente, um enunciado do tipo "Eu, fulano de tal, autorizo meu filho a .... Assinado ...". Esse eu se refere ao pai que assina e, como tal, responsabiliza-se pelo teor da autorização. No entanto, não designa o autor do texto, aquele que produziu o documento (a secretária, diretora, ou outro funcionário da escola que elaborou e padronizou o documento).

O exemplo das autorizações escolares coloca em evidência que o autor empírico do enunciado nem sempre é quem se responsabiliza por ele. É para resolver esse problema, entre outros, que Ducrot propõe a sua Teoria Polifônica da Enunciação. $\mathrm{O}$ autor começa por definir três funções diferentes, para o sujeito da enunciação: sujeito empírico (SE), locutor (L), e enunciador (E).

1 - O sujeito empírico (SE) é o autor efetivo, o produtor do enunciado: "El sujeto empírico es el autor efectivo, el productor del enunciado. Pero determinar quién es el autor efectivo del enunciado es mucho menos fácil de lo que se podría creer" (DUCROT, 1988, p. 16).

A dificuldade de determinar o sujeito empírico, para Ducrot (1988), não é um problema linguístico. O autor afirma que o linguista semanticista deve se preocupar com o sentido do enunciado, ou seja, o que interessa ao semanticista é o que está no enunciado e não as condições externas de sua produção.

2 - O locutor (L) é aquele que se apresenta como responsável pelo discurso, a quem se referem as marcas de $1^{\underline{a}}$ pessoa do discurso.

Por definição entendo por locutor um ser que é, no próprio sentido do enunciado, apresentado como seu responsável, ou seja, como alguém a quem se deve imputar a responsabilidade deste enunciado. É a ele que refere o pronome eu e as outras marcas de $1^{\mathrm{a}}$ pessoa. (DUCROT, 1987, p. 182)

Ducrot (1987) ainda afirma que o locutor pode ser totalmente diferente do sujeito empírico (o produtor efetivo do enunciado), já que o locutor é geralmente um personagem fictício a quem o enunciado atribui a responsabilidade de sua enunciação. O locutor "tiene marcas en el enunciado mismo: las de la primera persona (yo, mí, me, etc.) y en cierta medida, aquí, ahora...". (DUCROT, 1988, p. 17).

$\mathrm{O}$ autor ainda diferencia, no interior da própria noção de locutor, o "locutor enquanto tal" (L) e o "locutor enquanto ser do mundo" $(\lambda)$, ambos seres do discurso:

L é o responsável pela enunciação, considerado unicamente enquanto tendo esta propriedade. $\lambda$ é uma pessoa "completa" que possui, entre outras propriedades, a de ser a origem do enunciado - o que não impede que $\mathrm{L}$ e $\lambda$ sejam seres de discurso, constituídos no sentido do enunciado e cujo estatuto metodológico é, pois, totalmente diferente daquele do sujeito falante (este último deve-se a uma representação "externa" da fala, estranha àquela que é veiculada pelo enunciado). (DUCROT, 1987, p. 188)

Para explicar a distinção entre o L e $\lambda$, Ducrot recorre a diferentes fenômenos linguísticos, entre os quais os enunciados performativos explícitos, em enunciados do tipo "Eu te desejo boas férias". Neste enunciado, segundo Ducrot (1987, p. 190), a fórmula "Eu desejo..." é utilizada para uma asserção de ordem psicológica e o pronome $e u$ remete a $\lambda$ (locutor enquanto ser do mundo): "Não é enquanto locutor que se experimenta o desejo, mas enquanto ser do mundo, e independente da asserção que se faz dele". E acrescenta: "Por outro lado, o ato de desejar, que não existe senão na fala em que se realiza, pertence tipicamente a L: L realiza o ato de desejar afirmando que $\lambda$ deseja".

Por fim, Ducrot (1987) postula que L pertence ao comentário da enunciação feita globalmente pelo sentido e $\lambda$ pertence à descrição do mundo feita pelas asserções interiores ao sentido.

3 - Os enunciadores (E) são pontos de vista que o locutor apresenta em seu discurso, assumindo determinadas posições a respeito desses enunciadores: "En la teoría de la polifonía, por el contrario, el enunciado presenta una multitud de puntos de vista diferentes y el locutor toma una multitud de actitudes en relación con esos puntos de vista". (DUCROT, 1988, p. 68).

Ao enunciador, Ducrot associa o "centro de perspectiva" de Genette, ou seja, a pessoa de cujo ponto de vista são apresentados os acontecimentos, no texto literário: "Para distingui-lo do narrador, Genette diz que o narrador é 'quem fala', enquanto que o centro de perspectiva é "quem vê"” (DUCROT, 1987, p. 195).

Após haver identificado os diferentes seres do discurso, Ducrot $(1987 ; 1988)$ propõe a existência de dois tipos de polifonia presentes nos enunciados e, consequentemente, no discurso: a polifonia de enunciadores e a polifonia de locutores. A polifonia de enunciadores ocorre quando, no mesmo enunciado, são identificados pontos de vista diferentes, ou seja, enunciadores que são colocados em cena pelo locutor e perante os quais o locutor assume diferentes posições: ora aprovando-os, ora assimilando-se a eles, ora se opondo a eles.

A polifonia de locutores, por sua vez, se dá quando, num mesmo enunciado, verifica-se a existência de dois locutores distintos, eventualmente subordinados, conforme assinala Ducrot (1987). Neste trabalho, iremos 
nos deter, especificamente, sobre esse tipo de polifonia, em razão dos objetivos anteriormente apresentados.

\section{A polifonia de locutores}

A Polifonia de locutores é encontrada, segundo Ducrot (1987), no discurso relatado em estilo direto. Para o autor, nos enunciados com esse tipo de estilo, há uma pluralidade de responsáveis, "dados como distintos e irredutíveis" (DUCROT, 1987, p. 182). Assim, em enunciados do tipo

(2) Carla me falou: Eu irei cedo.

Há duas marcas de $1^{\underline{a}}$ pessoa, atribuídas a dois locutores distintos. O me é atribuído a um locutor responsável pelo discurso como um todo (L1), e o eu é atribuído a outro locutor (doravante L2).

Assim, é possível que uma parte de um enunciado imputado globalmente a um primeiro locutor seja, entretanto, imputado a um segundo locutor (do mesmo modo que, num romance, o narrador principal pode inserir no seu relato o relato que lhe fez um segundo narrador). (DUCROT, 1987, p. 185).

De acordo com Ducrot (1987), essa possibilidade de desdobramento do locutor permite não somente dar a conhecer o discurso atribuído a alguém como também produzir um eco imitativo, ou ainda organizar um teatro no interior da própria fala, ou que alguém se torne portavoz de um outro e empregue, no mesmo discurso, eus que remetem tanto ao porta-voz quanto à pessoa da qual é porta-voz.

$\mathrm{Na}$ polifonia de locutores, a enunciação é apresentada como dupla, ou seja, "o próprio sentido do enunciado atribuiria à enunciação dois locutores distintos, eventualmente subordinados" (DUCROT, 1987, p. 186). E, embora a enunciação seja ação de um sujeito falante, a imagem do enunciado que se apresenta é de uma hierarquia das falas, uma troca ou um diálogo entre os locutores, acrescenta o autor.

Retomando o exemplo (2), Carla me falou: Eu irei cedo, percebe-se a presença desses dois locutores distintos: $\mathrm{O}$ primeiro $\mathrm{L} 1=(\mathrm{me})-$ responsável pelo enunciado como um todo e o segundo L2 = (eu) a quem se atribui o relato "Eu irei cedo". Percebe-se também a hierarquia entre os locutores, uma vez que foi L1, o responsável pelo enunciado como um todo, que colocou em cena L2, responsável apenas pelo segmento "Eu irei cedo".

Certamente, do ponto de vista empírico, a enunciação é a ação de um único sujeito falante, mas a imagem que o enunciado dá dela é a de uma troca, de um diálogo, ou ainda de uma hierarquia de falas. Não há paradoxo, neste caso, senão se se confunde o locutor - que para mim é uma ficção discursiva - com o sujeito falante - que é um elemento da experiência. (DUCROT, 1987, p. 187)

Assim, para Ducrot (1987), a polifonia de locutores consiste no fenômeno da dupla enunciação mostrada no enunciado, caso específico do discurso relatado em estilo direto. No que se refere ao discurso relatado em estilo indireto, o autor não o considera como um caso de polifonia de locutores, já que não existiria a imagem, no enunciado, de uma dupla enunciação.

Ducrot ainda afirma que a diferença entre o estilo direto e o estilo indireto não é que o primeiro daria a conhecer a forma e o segundo só o conteúdo: "O estilo direto pode também visar só o conteúdo, mas para fazer saber qual é o conteúdo, escolhe dar a conhecer uma fala (ou seja, uma sequência de palavras imputadas a um locutor)" (DUCROT, 1987, p. 197).

Adotando uma perspectiva semelhante à de Ducrot, Moyano (2007) defende que existe um continuum nas possibilidades de reformulação do discurso alheio e que, dentro desse continuum, é possível reconhecer uma gradação que vai de um polo em que existe uma maior explicitação da voz alheia (o discurso relatado em estilo direto), a um polo onde a caracterização adquire um lugar mais preponderante (as nominalizações citativas e o discurso narrativizado ${ }^{1}$ ). Entre esses dois polos, estariam outras formas de utilização do discurso alheio, tais como o estilo indireto, as citações parciais e mistas, entre outras.

Para Moyano (2007), a diferença mais perceptível entre o estilo direto e estilo indireto é que, enquanto no primeiro se apresentam as palavras alheias com "aparente neutralidade", no segundo, as palavras relatadas sofrem algumas mudanças, já que o locutor que as cita acomoda-as a sua situação de comunicação. A autora afirma que é própria do estilo indireto a fusão de vozes e, concomitantemente, a subordinação sintática. Em razão disso, assume um posicionamento semelhante ao de Ducrot, com relação à distinção entre esses dois estilos de discurso relatado: "En efecto, a diferencia del ED, en que aparecen dos enunciadores, el estilo indirecto presenta un solo enunciador en la voz de un único locutor que cita indiretamente a outro". (MOYANO, 2007, p. 21).

Embora reconheçamos que no estilo indireto o locutor responsável pelo discurso incorpora às suas palavras o discurso alheio e reformula-o, apagando,

\footnotetext{
Para Moyano (2007), as nominalizações citativas são aquelas que se derivam de verbos que aludem a atos de fala, a exemplo de nomes como opinião, desautorização, crítica etc. Os discursos narrativizados, por sua vez, são definidos como um modo de reprodução ou pensamento do discurso alheio em que não se pode perceber nenhuma citação, nem reprodução alguma de texto original.
} 
inclusive, marcas dêiticas da fala do outro, permitimonos discordar de Ducrot (1987) e de Moyano (2007), considerando o estilo indireto como um caso de polifonia de locutores.

A principal razão pela qual consideramos o discurso relatado em estilo indireto um caso de polifonia de locutores é que, no próprio sentido do enunciado, o locutor responsável pelo discurso (L1) atribui a responsabilidade do discurso relatado a um outro ser do discurso, explicitamente identificado no próprio enunciado, como demonstrado no exemplo (3), a seguir.

\section{(3) Carlos me disse que viria amanhã}

No exemplo (3), o discurso relatado, em estilo indireto, "viria amanhã" é atribuído a outro ser do discurso (Carlos), diferente do locutor responsável pelo discurso como um todo (L1 - me). Como o discurso relatado, atribuído a um segundo ser (Carlos) foi introduzido por L1, também se observa uma espécie de eco imitativo ou um teatro no interior do enunciado, já que alguém se torna porta-voz de um "outro", a exemplo do que ocorre com o estilo direto.

Assim, preferimos considerar esse segundo ser do discurso como um segundo locutor (L2), já que não se trata de um ponto de vista atribuído a um ser diferente de L1 e que, no próprio sentido do enunciado, é explicitado e eventualmente subordinado a L1.

Convém ressaltar que, ainda que se apaguem marcas dêiticas da voz alheia no estilo indireto, o locutor a reconhece como tal e a identifica através de expressões e verbos dicendi, tais como o verbo dizer, no exemplo (3). A presença dos verbos e expressões dicendi, além de demarcar, no próprio sentido do enunciado, a subordinação da voz de um segundo locutor (L2) com relação à voz do locutor responsável pelo discurso como um todo (L1), pode indicar como L1 se posiciona diante do discurso de L2. Tal fenômeno ocorre não só no discurso relatado em estilo direto, mas também no relato em estilo indireto, como se pode observar nos exemplos (4) e (5), retirados do corpus analisado por Nascimento \& Oliveira (2011), descritos pelo projeto ESAGD.

\section{(4) Gênero ata}

"No caso da bacia do Paraíba do Sul, houve uma gestão exitosa através do CEIVAP e da AGEVAP, que nos permite estar aqui hoje distribuindo dinheiro para as prefeituras investirem na recuperação e conservação dos rios mineiros", avaliou o Secretário.

\section{(5) Gênero ata}

O conselheiro Erasmo salientou que os ótimos resultados da avaliação mostram a consistência do CEFET-RN e disse esperar que os indicadores venham a crescer a cada ano.
No exemplo (4), ocorre um caso de discurso relatado em estilo direto. Nesse exemplo, percebe-se a presença de dois locutores: o primeiro (L1) é o responsável por todo o enunciado, um locutor-narrador que está na terceira pessoa, e o segundo (L2) é o Secretário José Carlos, que é responsável por tudo que aparece escrito entre as aspas. L1 introduz o relato do segundo locutor (José Carlos) no estilo direto, entre aspas, e com a presença do verbo dicendi modalizador ${ }^{2}$ avaliar. Ao utilizar esse verbo dicendi, L1 deixa registrado em seu discurso como o relato de L2 deve ser lido, imprimindo um ponto de vista a respeito do discurso do segundo locutor: o discurso de L2 deve ser lido como uma avaliação. Assim, percebe-se como L1 posiciona-se com relação ao discurso do outro (L2), já que deixa registrado, em seu discurso, o modo como o discurso alheio deve ser lido.

Estratégia semelhante se faz notar no exemplo (5), em que se observa um discurso relatado em estilo indireto. O responsável pelo discurso como um todo (L1), locutornarrador que está na terceira pessoa, apresenta o discurso de um segundo locutor (L2 - conselheiro Erasmo) em estilo indireto, inicialmente através do verbo dicendi modalizador avaliativo ${ }^{3}$ salientar e, posteriormente, através da expressão dicendi modalizadora volitiva ${ }^{4}$ disse esperar. Ao fazer uso do verbo dicendi modalizador salientar e da expressão dicendi modalizadora disse esperar, L1 deixa expresso, no sentido do enunciado, como o relato de L2 deve ser lido, imprimindo um ponto de vista e uma avaliação a respeito do discurso do segundo locutor.

Os exemplos (4) e (5) ilustram o fato de que um locutor responsável pelo discurso como um todo (L1) pode trazer a voz alheia para dentro de seu próprio discurso, identificando essa voz como pertencente a outro ser do discurso ou mais especificamente a outro locutor (L2, L3 etc.), explicitamente dito no enunciado e, ao mesmo tempo, assumir posicionamentos com relação ao discurso alheio. Essa é, portanto, uma característica comum tanto ao discurso relatado em estilo direto como ao discurso relatado em estilo indireto, o que justifica a nossa opção por tratarmos ambos como casos de polifonia de locutores.

\footnotetext{
2 Consideramos verbos e expressões dicendi, todos os verbos e expressões que se utilizam para introduzir o discurso relatado. Classificamos esses verbos e expressões em dois grandes grupos, a saber: 1) modalizadores aqueles que, além de introduzir o discurso relatado, apresentam o modo como esse discurso deve ser lido (portadores, portanto, da síntese léxica "dizer + modalidade"); e 2) não modalizadores - aqueles que introduzem o discurso relatado, mas não apresentam nenhuma noção de modalidade em seu conteúdo semântico, logo indicam, apenas, um ato de fala. (NASCIMENTO, 2005).

3 Os modalizadores avaliativos apresentam o conteúdo do enunciado como um julgamento ou ponto de vista, excetuando-se qualquer avaliação de caráter epistêmico ou deôntico. (NASCIMENTO, 2005).

4 Os modalizadores deônticos volitivos apresentam o conteúdo do enunciado como uma vontade ou desejo, de natureza deôntica (NASCIMENTO; SILVA, 2012).
} 
No que se refere à diferença entre os dois estilos de discurso relatado, Bakhtin (2002b) considera que essa diferença é de grau e orientação de análise, ou seja, no estilo direto a análise do discurso do outro pelo narrador é menor do que no indireto. E acrescenta que esse discurso integra elementos e matizes que o outro deixa de lado.

O discurso indireto ouve de forma diferente o discurso de outrem; ele integra ativamente e concretiza na sua transmissão outros elementos e matizes que os outros esquemas deixam de lado. Por isso transposição literal, palavra por palavra, da enunciação construída segundo um outro esquema só é possível nos casos em que a enunciação direta já se apresenta na origem como uma forma algo analítica - isso, naturalmente, dentro dos limites das possibilidades analíticas do discurso direto. A análise é a alma do discurso indireto. (BAKHTIN, 2002b, p. 159)

O autor ainda acrescenta que a análise, no discurso indireto, pode ser de conteúdo ou de expressão: a primeira apreende o discurso do outro no plano meramente temático e a segunda "abrange grandes possibilidades às tendências à replica e ao comentário no contexto narrativo, ao mesmo tempo que conserva uma distância nítida e estrita entre as palavras do narrador e palavras citadas" (BAKHTIN, 2002b, p. 161).

Estamos de acordo com Bakhtin no sentido de que a diferença entre o estilo direto e indireto é uma questão de grau e orientação de análise. Inicialmente, pensávamos que essa análise consistiria em um maior ou menor comprometimento com o relato de outrem pelo locutor (ou narrador, nas palavras de Bakhtin): no estilo direto, o locutor responsável pelo discurso (L1) não se comprometeria com o discurso dos outros locutores introduzidos em seu discurso, uma vez que não assumiria a responsabilidade pelo relato dos outros locutores; já no estilo indireto, L1 se comprometeria com os relatos dos outros locutores, porque tornaria seu o discurso do outro, incorporando as palavras alheias e deixando de sinalizá-las (com aspas ou travessão, por exemplo) (cf. NASCIMENTO, 2005).

No entanto, as análises realizadas nos últimos corpora descritos pelo projeto ESAGD têm nos mostrado que não se trata de uma questão de maior ou menor comprometimento, assimilação ou distanciamento. A assimilação, o distanciamento e a avaliação do discurso relatado, por parte do locutor responsável pelo discurso, dão-se muito mais pela presença de outros elementos linguístico-discursivos, como as aspas de diferenciação ${ }^{5}$,

\footnotetext{
5 As aspas, além de assinalar o discurso relatado em estilo direto, possuem outras diferentes funções, permitindo, inclusive, ao locutor se distanciar do que ele introduz no discurso, como propõe Authier-Revuz (1998). Nesse sentido, Koch $(2001$, p. 53) afirma que as aspas de diferenciação são aquelas que um locutor utiliza para mostrar que se distingue daquele que usa a palavra - "que somos 'irredutíveis' às palavras mencionadas".
}

os verbos dicendi, entre outras estratégias linguísticodiscursivas, do que pelo fato de esse discurso ter sido apresentado em um ou outro estilo. O exemplo (6), retirado do corpus de Batista (2010), ilustra como L1 pode assumir um posicionamento de distanciamento com relação ao discurso alheio, ainda que o tenha apresentado em estilo indireto.

\section{(6) Gênero Relatório}

A SRC, por meio da Nota Técnica no 142/2006-SRCSFE/ANEEL, sugeriu a inclusão, na Resolução $\mathrm{n}^{0}$ 246/02 de dispositivo que permita a autodeclaração para consumidores que residem em imóveis de terceiros [...].

No exemplo (6), o locutor responsável pelo discurso como um todo (L1), locutor-narrador em terceira pessoa, introduz em seu texto o discurso de um segundo locutor $(\mathrm{L} 2=\mathrm{SRC})$, através do verbo dicendi modalizador sugerir. $\mathrm{O}$ fato de o discurso relatado ter sido apresentado como uma sugestão, por parte de L1, isenta este primeiro locutor de qualquer responsabilidade com relação ao dito do segundo locutor, mesmo estando o discurso relatado em estilo indireto, o que poderia implicar, numa primeira análise, em uma assimilação de L1 com o discurso de L2. Em outras palavras, como o verbo sugerir é um modalizador epistêmico quase-asseverativo, com uma síntese semântica do tipo "dizer + possibilidade", o discurso de L2 é apresentado como algo possível, e não como algo certo. Assim, L1 não pode ser responsabilizado pelo dito de L2, já que o apresenta como algo sugerido, logo possível.

Esse exemplo (6) serve para demonstrar que o fato de um relato estar no estilo indireto não significa que L1 irá assimilar esse discurso. Da mesma forma, não se pode afirmar que estilo direto implica, necessariamente, em um distanciamento de L1 com relação ao discurso relatado. No entanto, é importante assinalar que, mesmo que os posicionamentos assumidos por L1 em um e outro estilo possam ser de diferentes naturezas, permanece a diferença de grau de orientação e análise a que se refere Bakhtin (2002), já que no estilo indireto L1 incorpora as palavras de outro locutor, tornando-as suas, e apagando, na maior parte das vezes, as marcas dêiticas alheias.

No entanto, em ambos os casos, podemos considerar que ocorre uma polifonia de locutores, já que L1 atribui o discurso relatado a outro ser de discurso, explicitamente identificado e mostrado no próprio sentido do enunciado.

\section{Polifonia e impessoalidade discursiva}

Os exemplos (4), (5) e (6), analisados anteriormente e referentes aos gêneros ata e relatório, apresentam um 
fenômeno bastante peculiar nos gêneros do universo empresarial/oficial e do universo acadêmico: a impessoalidade discursiva, ou mais especificamente, a apresentação de um locutor-narrador, em terceira pessoa, responsável pelo discurso como um todo.

A presença do texto, na terceira pessoa, característica do estilo linguístico e da própria estrutura composicional da maioria dos gêneros desses dois universos, tenta conferir um caráter de objetividade ao texto, no sentido de que o dito parece apresentar-se a si próprio. Fenômeno similar foi observado por Garcia Negroni (2009), em textos da História e em gêneros acadêmicos, em língua espanhola.

Nesse sentido, é importante considerar que, segundo Ducrot (1988), é possível fabricar enunciados sem L, ou seja, sem um locutor em primeira pessoa. Citando Benveniste, Ducrot (1987) afirma que esses enunciados estão para a história em oposição aos outros, onde está marcado o locutor, que pertencem ao discurso. Como exemplo ele cita os discursos do general De Gaule que usava todos os seus discursos em terceira pessoa. Ao retirar qualquer marca de origem pessoal da sua enunciação, o general a fazia aparecer como se fosse responsabilidade da História e não dele. Na verdade, o uso da impessoalidade no discurso é uma estratégia argumentativa que pretende isentar de responsabilidades o locutor, ou ainda, escondê-lo por trás da máscara da imparcialidade, como comprovamos em nossas investigações sobre a notícia jornalística (NASCIMENTO, 2005).

Sem dúvida, como afirma García Negroni, "las huellas de la presencia del locutor en su discurso no se agotan en los pronombres yo/tú, en los comentarios subjetivos y en los diferentes adverbios deícticos espaciales y temporales" (GARCÍA NEGRONI, 2009, p. 21). Nesse sentido, temos verificado, na descrição de diferentes géneros dos universos acadêmico e empresarial/oficial descritos pelo projeto ESAGD, que ainda que um texto se apresente de forma impessoalizada com um locutornarrador em terceira pessoa, responsável pelo discurso como um todo (L1), a subjetividade desse locutor se manifesta no texto através de outras marcas linguísticodiscursivas, a exemplo dos verbos dicendi.

Ainda convém observar que o locutor-narrador (L1) dos gêneros pertencentes a esses universos de atividade humana possui características muito peculiares, já que se trata de um locutor que apresenta todo tipo de informações, pretendendo-se objetivo ou imparcial: declarações, discussões, decisões, processos, procedimentos, resultados, relatos e demais temas próprios da vida acadêmica e da vida empresarial, conforme seja a atividade a que se refere o gênero ou o texto em questão. Isso se pode observar, no exemplo (7), a seguir, retirado do corpus analisado por Lima (2009).

\section{(7) Gênero resumo acadêmico}

A charge denuncia algo que é dito de forma obscura utilizando o humor como subsídio capaz de camuflar a mensagem no propósito de não transparecer acusações e críticas direcionadas a pessoas ou situações, por isso, a presença de ambiguidade, contradições, ironias, e outros aspectos que marcam este gênero.

No exemplo (7), pertencente ao gênero resumo acadêmico, observa-se que o texto apresenta-se de maneira impessoal, com um narrador-locutor em terceira pessoa (L1). No entanto, a utilização do verbo denunciar, modalizador avaliativo, apresentando o conteúdo do enunciado como uma denúncia, revela um posicionamento do próprio locutor com relação ao dito. Além do uso desse modalizador, a presença do locutor faz-se perceber pela utilização do operador argumentativo "por isso", que é utilizado para estabelecer uma relação causa-consequência, no interior do enunciado: o motivo de existir ambiguidade, contradições e ironias no gênero charge é que o referido gênero denuncia algo que é dito de forma obscura, utilizando o humor como subsídio capaz de camuflar a mensagem no propósito de não transparecer acusações e críticas direcionadas a pessoas ou situações.

Assim, o fato de o locutor responsável pelo discurso apresentar-se em terceira pessoa não elimina sua subjetividade, o que pode ser percebido através de outros elementos linguístico-discursivos presentes na materialidade linguística. No entanto, essa estratégia discursiva constrói a imagem de um locutor que parece estar à margem do discurso e, por isso, o discurso parece apresentar-se a si próprio, gerando a ideia de objetividade ou neutralidade.

A impessoalidade também pode dar-se, no texto, através da evocação, por parte do locutor responsável pelo discurso, da voz do ON-locuteur (SE-locutor), fenômeno que trataremos a seguir.

\subsection{O fenômeno do SE-locutor}

Em alguns gêneros do universo empresarial/oficial e do universo acadêmico, já foi possível verificar que o locutor responsável pelo discurso (L1), além dos relatos em estilo direto e indireto, pode colocar em cena, no sentido dos enunciados, a voz de um locutor impessoalizado, demarcado pela presença de um verbo dicendi seguido da partícula se, em construções do tipo diz-se, afirma-se etc. Esse fenômeno foi observado, principalmente, no gênero ata administrativa-acadêmica, em língua espanhola.

O SE-locutor, ON-locuteur nos estudos de Anscombre (2005; 2010), constitui-se em uma voz colocada em cena, no próprio enunciado, pelo locutor responsável pelo discurso, introduzida por marcadores 
de citações genéricos (segundo, diz-se etc.) e que pode estar associada, em alguns contextos, à voz da doxa (nos provérbios, por exemplo) ou a uma voz coletiva, na qual o locutor como ser do mundo $(\lambda)$ pode ou não estar incluído.

Anscombre (2010, p. 42) afirma que o se-locutor é um fenômeno que possui três propriedades básicas: ser uma voz constitutiva do discurso e introduzida pelo locutor; tratar-se de uma voz coletiva; constituir-se em uma voz anônima.

Rappelons qu'un ON-locuteur est caractérisé par trois propriétés: a) Il s'agit d'une voix (ici constitutive) du discours mis en place par le locuteur; b) Cette voix est collective; c) Cette voix est anonyme. (ANSCOMBRE, 2010, p. 42)

No gênero ata administrativa-acadêmica em língua espanhola, observamos que a voz do SE-locutor, por tratarse de uma voz genérica e impessoalizada, geralmente está associada ao próprio conselho administrativo-acadêmico a que se refere o texto, tentando criar, no sentido do enunciado, uma noção de objetividade, como se pode observar no exemplo (8) (NASCIMENTO, 2014).

\section{(8) Ata administrativa-acadêmica (espanhol)}

Se resuelve votar la asignación de las rentas disponibles y se reafirma el criterio de continuar con el listado de ad honorem, por lo que los beneficiados son los siguientes: (...).

No exemplo (8), o locutor responsável pelo discurso como um todo (L1) coloca em cena, no sentido do enunciado, a voz de um SE-locutor, através do verbo dicendi reafirmar. $\mathrm{O}$ verbo dicendi utilizado possui a síntese léxica "dizer + certeza", por isso se constitui em um modalizador epistêmico asseverativo ${ }^{6}$ e, por conseguinte, apresenta a voz do SE-locutor como algo certo ou verdadeiro.

Como o verbo dicendi está em uma construção impessoal - se reafirma - o efeito de sentido que se gera no enunciado é de uma pretensa objetividade, ou seja, a introdução do SE-locutor produz a ideia de que o ponto de vista expresso no enunciado apresenta a si mesmo. Nesse exemplo, o SE-locutor, no sentido do enunciado e no próprio gênero ata administrativo-acadêmica, representa a voz de uma coletividade, que poderia atribuir-se discursivamente ao próprio conselho ou à junta departamental a que se refere o texto.

Ainda é importante observar que o uso do verbo dicendi reafirmar produz, no sentido do enunciado, uma avaliação epistêmica do locutor responsável pelo discurso (L1 - locutor-narrador) sobre o conteúdo do segmento atribuído ao SE-locutor, uma voz coletiva: "Este verbo, en este contexto, adquiere una función aseverativa bastante peculiar, sobre todo si se considera que los consejos académicos son autoridades legalmente constituidas para tomar decisiones, crear resoluciones, afirmarlas y reafirmarlas" (NASCIMENTO, 2014, p. 12).

A evocação da voz do SE-locutor também pode ser observada no gênero relatório, em língua portuguesa, no corpus coletado por Batista (2010). O exemplo (9), a seguir, demonstra essa ocorrência.

\section{(9) Gênero relatório}

E) A proposta do Ministério das Cidades para o Plano de Comunicação da $3^{\text {a }}$ Conferência foi apresentada e sugeriu-se a possibilidade de acrescentar entre os mecanismos de divulgação outdoors para serem colocados nos estados.

No exemplo (9), retirado do gênero relatório, o locutor responsável pelo discurso (L1 - locutor-narrador), coloca em cena um SE-locutor, através do verbo dicendi modalizador epistêmico quase-asseverativo ${ }^{7}$ sugerir, seguido da partícula se. Também neste caso, o ponto de vista ao SE-locutor, responsável pelo segmento "a possibilidade de acrescentar entre os mecanismos de divulgação outdoors para serem colocados nos estados" aparece como uma voz coletiva, não identificada explicitamente no próprio enunciado.

Considerando que o relatório em questão se refere a uma reunião de uma coordenação executiva de uma conferência nacional, parece-nos possível atribuir, discursivamente, essa voz do SE-locutor à coletividade dos presentes na reunião. No entanto, o fato dessa voz ser apresentada em uma construção impessoal - sugeriuse - o efeito de sentido que se gera no enunciado é de uma pretensa objetividade, ou seja, ou a introdução do SE-locutor produz a ideia de que o referido ponto de vista apresenta a si mesmo.

Há de se observar ainda que a expressão utilizada é constituída pelo verbo dicendi modalizador quaseasseverativo sugerir, portador da síntese léxica "dizer + possibilidade". Ao apresentar a voz do SE-locutor com um verbo quase-asseverativo, L1 não se compromete com

\footnotetext{
6 Os modalizadores epistêmicos asseverativos são aqueles modalizadores que apresentam o conteúdo do enunciado como algo certo ou verdadeiro. (NASCIMENTO; SILVA, 2012). São classificados como verbos e expressões dicendi modalizadores quase-asseverativos aqueles verbos e expressões portadores da síntese léxica "dizer + certeza", que além de introduzir o discurso relatado, modaliza-o, apresentando-o como algo certo ou verdadeiro (NASCIMENTO, 2005).

7 Os modalizadores epistêmicos quase-asseverativos, por sua vez, apresentam o conteúdo do enunciado como algo possivelmente certo ou verdadeiro (NASCIMENTO; SILVA, 2012). São classificados como verbos e expressões dicendi modalizadores quase-asseverativos aqueles verbos e expressões portadores da síntese léxica "dizer + possibilidade" que, além de introduzir o discurso relatado, modaliza-o, apresentando-o como algo provável ou possível e, nesse sentido, não comprometem o locutor responsável pelo discurso como um todo (NASCIMENTO, 2005).
} 
o discurso apresentado, tampouco o assimila, mantendo uma certa distância com relação ao dito. Esse não comprometimento confirma-se pela própria utilização da palavra possibilidade, no discurso do SE-locutor.

Os exemplos (8) e (9), acima analisados, levamnos a acreditar que, nos gêneros ata administrativoacadêmica (em espanhol) e relatório, (em português), o locutor responsável pelo discurso (L1 - locutor-narrador em terceira pessoa) não faz parte, necessariamente, desta voz coletiva, embora se posicione com respeito a ela: no exemplo (8), o posicionamento é de assimilação ou concordância, por conta do uso do verbo asseverativo reafirmar; e no exemplo (9), o posicionamento é de distanciamento ou não comprometimento, em razão da utilização do verbo quase-asseverativo sugerir.

De fato, em ambos gêneros não foram encontradas marcas de que o locutor-narrador em terceira pessoa (L1) pertença a esta voz coletiva, o que não implica que isso não possa ocorrer em outros gêneros do universo empresarial/oficial ou do universo acadêmico. No entanto, a utilização de diferentes verbos dicendi modalizadores revelam posicionamentos ou índices de subjetividade de L1, com relação a essa voz coletiva, apresentada sob a forma de um SE-locutor.

Por fim, assinalamos que o fenômeno da evocação do SE-locutor por parte de um locutor responsável pelo discurso (L1) constitui-se um caso particular de polifonia. Não nos parece possível, pelo menos neste momento, incluí-lo dentro dos casos de polifonia de locutores (relatos em estilo direto e indireto), uma vez que essa voz coletiva não é atribuída, explicitamente, a um segundo locutor, enquanto ser do discurso, no próprio enunciado. Isso não impede, obviamente, que identifiquemos de onde parte essa voz coletiva, o que pode ser feito considerando-se as características sóciodiscursivas do gênero em questão.

\section{Considerações finais}

Nas investigações realizadas (ou em realização) pelo projeto ESAGD, conforme se pode observar nos exemplos (4), (5), (6), (7), (8) e (9), analisados anteriormente, temos verificado que o fenômeno da polifonia, em especial da polifonia de locutores, produz diferentes efeitos de sentido, nos diferentes gêneros do universo empresarial/oficial e do universo acadêmico: a criação do caráter de objetividade no discurso, a assimilação ou o distanciamento de vozes alheias, a avaliação axiológica dessas vozes, entre outros efeitos de sentido.

Também temos verificado que a polifonia de locutores, tanto na forma de estilo direto como de estilo indireto, tem sido um dos tipos de polifonias mais recorrentes nos diversos gêneros investigados. Acreditamos que haja uma razão bastante específica para a ocorrência desse tipo de fenômeno nesses dois universos de atividade humana.

No universo científico, de maneira específica, a utilização da voz alheia, de pesquisas e de investigações anteriormente realizadas, é utilizada não só para justificar as novas investigações, como também é objeto de pesquisa. Muitas vezes, é a própria voz da ciência que é objeto de investigação. Nesse sentido, o fazer científico não se constrói no acaso, mas em consonância com a voz do outro, devidamente apresentado e identificado discursivamente. No universo empresarial, por sua vez, faz-se necessário relatar discussões, análises, tomadas de decisões e outras ações que fundamentam a ação de administrar, coordenar ou liderar. Isso se dá, de maneira especial, em gêneros como a ata e o relatório, propícios para esse tipo de registro.

Concomitante com a polifonia de locutores, também temos verificado, em alguns gêneros, a presença do SElocutor, uma voz coletiva não identificada, utilizada pelo locutor responsável pelo discurso para gerar o efeito de objetividade discursiva, no sentido dos enunciados. Nesse sentido, convém ressaltar que o próprio locutor, responsável pelo discurso como um todo, nos gêneros dos universos empresarial/oficial e acadêmico, apresenta-se, em grande parte das vezes, de maneira impessoalizada, sob a forma de um locutor-narrador em terceira pessoa que apresenta acontecimentos, processos, ações, decisões, resultados, entre outros conteúdos próprios desses universos de atividade humana.

A criação da noção de objetividade, gerada pela presença de um locutor-narrador em terceira pessoa, pela introdução da voz alheia ou de um SE-locutor não significa um distanciamento total do locutor responsável pelo discurso (L1) com relação ao dito, muito menos um apagamento de sua existência. Obviamente que esses fenômenos criam, no sentido dos enunciados e nos diferentes gêneros, a ideia de que o discurso apresenta-se a si próprio e, nesse sentido, parece tornar-se objetivo, uma estratégia bastante eficaz para a manutenção do próprio status quo tanto da atividade acadêmica, como da atividade empresarial/oficial.

No entanto, a forma como as diferentes vozes são apresentadas no discurso (com a utilização ora do estilo direto, ora do estilo indireto, ora do SE-locutor), através de diferentes tipos de verbos ou expressões dicendi, muitos deles modalizadores, acabam por denunciar, no próprio sentido do enunciado, posicionamentos do locutor responsável pelo discurso (não somente com relação ao seu dizer, mas também com relação à voz alheia). Essas diferentes formas de introduzir a voz alheia no discurso revelam, nesse sentido, marcas de subjetividade deste locutor que se pretende objetivo, porta-voz da ciência ou dos fatos da administração pública e privada. 


\section{Referências}

ANSCOMBRE, Jean-Claude. Le on-locuteur: une entité aux multiples visages. In: BRES, Jacques et al. Dialogisme et polyphonie. Paris: De Boeck Supérieux (Champ linguistiques), 2005. p. 75-94.

ANSCOMBRE, Jean-Claude. Auteur d'une définition linguistique des notions de voix collective et de on-locuteur. Recherches Linguistique, n. 31, p. 29-64, 2010.

BAKHTIN, Mikhail. Problemas da poética de Dostoiévski. Rio de Janeiro: Ed. Forense-Universitária, 2002a.

BAKHTIN, Mikhail. Marxismo e filosofia da linguagem. 10. ed. São Paulo: Hucitec, 2002b.

BATISTA, Silvana Lino. Estratégias semântico-argumentativas no gênero textual/discursivo relatório. João Pessoa: UFPB, 2010. (Relatório de pesquisa PIBIC)

DUCROT, Oswald. O dizer e o dito: revisão técnica da tradução Eduardo Guimarães. Campinas: Pontes, 1987.

DUCROT, Oswald. Polifonia y Argumentación: Conferencias del Seminario Teoría de la Argumentación y Análisis del Discurso. Cali: Universidad del Valle, 1988.

GARCIA NEGRONI, María Marta. Dialogismo y polifonía enunciativa. Apuntes para una reelaboración de la distinción discurso/historia. Páginas de Guarda, n. 7, p. 15-31, 2010.

LIMA, Geziel de Brito. A argumentatividade no gênero resumo acadêmico: operadores argumentativos e modali- zadores discursivos. João Pessoa, UFPB, 2009. (Relatório de pesquisa)

MOYANO, Sara Inés. El discurso narrativizado y las nominalizaciones citativas: dos formas solapadas de caracterizar la palabra ajena. Tesis (Magíster en Lingüística) - Facultad de Humanidades y Ciencias de la Educación, Universidad Nacional de La Plata, La Plata, 2007.

NASCIMENTO, Erivaldo Pereira do. Jogando com as vozes do outro: a polifonia - recurso modalizador - na notícia jornalística. 2005. Tese (Doutorado em Letras) - Centro de Ciências Humanas, Letras e Artes, Universidade Federal da Paraíba, João Pessoa, 2005.

NASCIMENTO, Erivaldo Pereira do. Modalización en el género "acta administrativo-académica". Buenos Aires: UBA, 2014. (no prelo)

NASCIMENTO, Erivaldo Pereira do; OLIVEIRA, Pricila Rafaela dos Santos. A polifonia como estratégia argumentativa no gênero ata. João Pessoa: UFPB, 2011. (Relatório de pesquisa)

NASCIMENTO, Erivaldo Pereira do; SILVA, Joseli Maria da. O fenômeno da modalização: estratégia semântico-argumentativa e pragmática. A argumentação na redação comercial e oficial: estratégias semântico-discursivas em gêneros formulaicos. João Pessoa: Editora da UFPB, 2012.

Recebido: 16 de novembro de 2014

Aprovado: 08 de abril de 2015

Contato: erypn@hotmail.com 